low rates. Low levels of patients are taking advantage of existing immunisation programmes. Patient recall of previous vaccination may not be sufficient to imply immunity. A systematic process for assessing patients' vaccination status and active encouragement of vaccination programmes should be undertaken in the outpatient setting.

Abstract PTU-121 Table 1 Questionnaire responses

\begin{tabular}{|c|c|c|c|c|c|}
\hline$n=91$ & $\begin{array}{l}\text { VZV } \\
\text { disease }\end{array}$ & $\begin{array}{l}\text { HBV infection } \\
\text { or vaccination }\end{array}$ & $\begin{array}{l}\text { Pneumococcal } \\
\text { vaccine }\end{array}$ & $\begin{array}{l}\text { Influenza } \\
\text { vaccine }\end{array}$ & $\begin{array}{l}\text { HPV vaccine } \\
(n=45)\end{array}$ \\
\hline Yes & $63(69 \%)$ & $15(16 \%)$ & $8(9 \%)$ & $28(31 \%)$ & $0(0 \%)$ \\
\hline No & $10(11 \%)$ & $58(64 \%)$ & $78(86 \%)$ & $61(67 \%)$ & $37(82 \%)$ \\
\hline Unknown & $18(20 \%)$ & 17 (19\%) & $4(4 \%)$ & $2(2 \%)$ & 7 (16\%) \\
\hline No answer & - & $1(1 \%)$ & $1(1 \%)$ & - & $1(2 \%)$ \\
\hline $\begin{array}{l}\text { Complete } \\
\text { screening }\end{array}$ & $70(77 \%)$ & $10(11 \%)$ & NA & NA & NA \\
\hline
\end{tabular}

Competing interests None declared.

\section{PTU-122 A TRIAL WITH MERCAPTOPURINE FOLLOWING AZATHIOPRINE INTOLERANCE IS A SAFE TREATMENT STRATEGY FOR THE MAJORITY OF PATIENTS WITH IBD}

doi:10.1136/gutjnl-2012-302514c.122

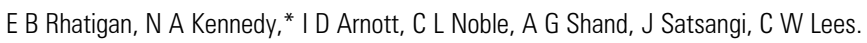
Gastrointestinal Unit, Molecular Medicine Centre, Western General Hospital, Edinburgh, UK

Introduction Azathioprine intolerance (AZA-I) leads to withdrawal of therapy in up to $30 \%$ of patients with IBD. Smaller case series demonstrated that mercaptopurine (MP) could be a well tolerated alternative in selected patients. ${ }^{1}$ This study aims to further assess its tolerability, in a larger cohort of AZA-I patients, over a longer period of time, and to re-evaluate potential factors predictive of tolerance. Methods A retrospective audit was made of 137 patients with IBD (78 women, median age at diagnosis 32 years, 78 with CD, 59 with UC) who had been intolerant of AZA and then subsequently treated with MP

Results MP was tolerated by $58 \%$ of AZA-I patients (median followup 937 days, median dose $0.91 \mathrm{mg} / \mathrm{kg}$ ). Tolerance was highest in patients with AZA related gastrointestinal intolerance $(66 \%)$ and hepatotoxicity (61\%), and lowest in patients with AZA related flulike illness (40\%). The number of patients with AZA induced neutropenia and pancreatitis were too small to draw firm conclusions (see Abstract PTU-122 table 1). Age at diagnosis was significantly associated with tolerability. Patients intolerant of MP were younger ( 28 vs 33 yro; $p=0.024$ ) and of those under the age of 40 only $55 \%$ tolerated MP compared with $69 \%$ of those aged 40 years or over ( $\mathrm{p}=$ Azathioprine-intolerant patients, subsequently treated with mercaptopurine (AZA-I/MP) grouped by azathioprine intolerance

Conclusion Consistent with previous data, this, the largest series to date, with substantial follow- up, has shown that MP is a safe alternative for up to $60 \%$ of AZA-I patients, including some with a previous major intolerance. Patients with previous gastrointestinal intolerance or hepatotoxicity may be more likely to tolerate a trial of MP.

Competing interests None declared.

\section{REFERENCE}

1. Lees, et al. Aliment Pharmacol \& Ther 2007;27:220-7.

\section{PTU-123 ACUTE SEVERE ULCERATIVE COLITIS: THE LAST 12 YEARS IN EDINBURGH}

doi:10.1136/gutjnl-2012-302514c.123

N A Kennedy, ${ }^{*}$ J E Van Ross, N C Hare, G-T Ho, H E Drummond, A G Shand, I D Arnott, C W Lees, J Satsangi. Gastrointestinal Unit, Molecular Medicine Centre, Western General Hospital, Edinburgh, UK

Introduction Acute severe ulcerative colitis (ASUC) remains a common reason for urgent colectomy, yet there are relatively few large cohort studies exploring prognosis and outcome. ${ }^{1-3}$ This study aims to examine presentation and management of ASUC in the Western General Hospital, a tertiary referral centre in Edinburgh and to identify prognostic factors.

Methods Patients were identified from a large database of participants in genetic studies in Edinburgh, as well as from two previous small cohorts of ASUC studied in Edinburgh. More recent cases were found from minutes of a weekly IBD meeting. Cases were included if they met the standard clinical, radiological and pathological criteria for ulcerative colitis and required an admission for 3 days or more requiring intravenous corticosteroids and/or colectomy. Two cohorts were analysed, one with full clinical detail (97 admissions in 86 patients) and one with more basic detail (444 admissions in 323 patients).

Results Overall colectomy rate was $31.8 \%$. Haemoglobin, $\mathrm{C}$ reactive protein and albumin at days 0 and 3 were significant predictors of colectomy in both cohorts ( $p<0.05$ in each case), while in the detailed cohort day 3 but not day 0 stool frequency was predictive ( $p<0.001$ and 0.81 respectively). A simple score was derived to predict colectomy at admission based on disease extent, albumin and CRP. Scores of 0, 1, 2 and 3 corresponded to risks for colectomy

Abstract PTU-122 Table 1

\begin{tabular}{|c|c|c|c|c|c|c|c|c|c|}
\hline \multirow[b]{2}{*}{$\begin{array}{l}\text { Type of azathioprine } \\
\text { intolerance }\end{array}$} & \multirow[b]{2}{*}{$\mathbf{n}$} & \multirow{2}{*}{$\begin{array}{l}\text { Proportion with } \\
\text { mercaptopurine } \\
\text { tolerance (\%) }\end{array}$} & \multicolumn{6}{|c|}{ Type of mercaptopurine intolerance } & \multirow{2}{*}{$\begin{array}{l}\text { Proportion of patients where } \\
\text { intolerance of mercaptopurine } \\
\text { same as for azathioprine (\%) } \\
30 / 55(55 \%)\end{array}$} \\
\hline & & & $\begin{array}{l}\text { GI } \\
\text { Intolerance }\end{array}$ & $\begin{array}{l}\text { Flu-like } \\
\text { illness }\end{array}$ & Hepatotoxicity & Neutropenia & Pancreatitis & Other & \\
\hline GI Intolerance* & 67 & $44 / 67(66 \%)$ & 14 & 2 & 0 & 5 & 2 & 0 & $14 / 23(61 \%)$ \\
\hline Flu-like illness & 35 & $14 / 35(40 \%)$ & 4 & 10 & 3 & 2 & 0 & 2 & $10 / 21(48 \%)$ \\
\hline Hepatotoxicity & 18 & $11 / 18(61 \%)$ & 1 & 1 & 2 & 2 & 0 & 1 & $2 / 7(29 \%)$ \\
\hline Neutropenia & 4 & $3 / 4(75 \%)$ & 0 & 0 & 0 & 1 & 0 & 0 & $1 / 1(100 \%)$ \\
\hline Pancreatitis & 3 & $2 / 3(67 \%)$ & 0 & 0 & 0 & 0 & 1 & 0 & $1 / 1(100 \%)$ \\
\hline Other $†$ & 8 & $6 / 8(75 \%)$ & 0 & 0 & 0 & 0 & 0 & 2 & $2 / 2(100 \%)$ \\
\hline Unknown & 2 & $0 / 2(0 \%)$ & 1 & 1 & 0 & 0 & 0 & 0 & NA \\
\hline
\end{tabular}

*Nausea, vomiting, abdominal pain, diarrhoea.

†Rash, Alopecia, Headaches, Itch, anaemia and acute kidney injury, acne. 
of $10 \%, 31 \%, 61 \%$ and $75 \%$. For day 3 parameters, both the Edinburgh acute colitis (Ho) score (Abstract PTU-123 figure 1) and Travis criteria performed well.

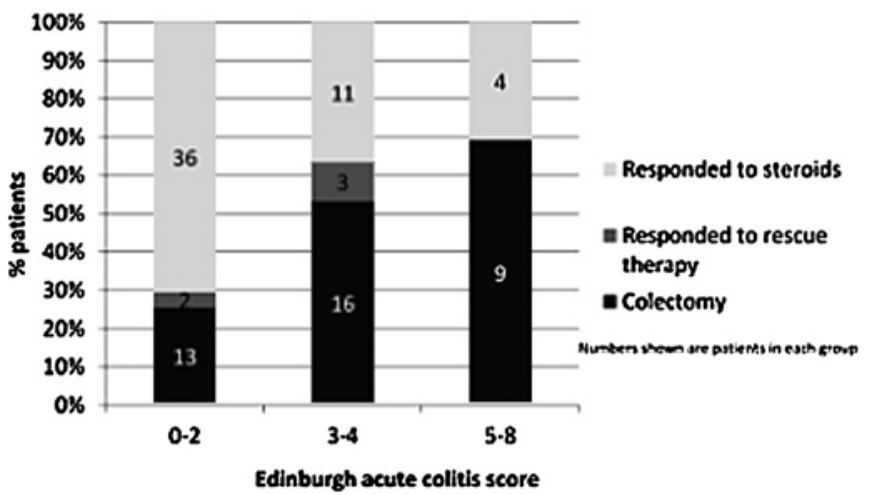

Abstract PTU-123 Figure 1

Conclusion ASUC remains an important cause of colectomy. This study confirms the prognostic value of the Ho score and Travis criteria at day 3 , but also indicates that day 0 CRP and albumin are strong predictors of outcome.

Competing interests None declared.

\section{REFERENCES}

Dinesen LC, et al. J Crohns Colitis 2010;4:431-7.

2. Ho GT, et al. Aliment Pharmacol Ther 2004:19:1079-87.

3. Turner D, et al. Clin Gastroenterol Hepatol 2007:5:103-10.

\section{PTU-124 ARE PSEUDOPOLYPS THE SOURCE OF TUMORIGENIC MUTATIONS IN ULCERATIVE COLITIS?}

doi:10.1136/gutjnl-2012-302514c.124

${ }^{1} \mathrm{~N}$ Jawad, ${ }^{*} \mathrm{~T}$ Graham, ${ }^{3} \mathrm{M}$ Novelli, ${ }^{3} \mathrm{M}$ Rodriguez-Justo, ${ }^{4} \mathrm{R}$ Feakins, ${ }^{1} \mathrm{~A}$ Silver, ${ }^{1} \mathrm{~N}$ Wright, ${ }^{1} \mathrm{~S}$ McDonald. 'Digestive Diseases Department, Blizard Institute, Barts and The London School of Medicine and Dentistry, Queen Mary, University of London, London, UK; ${ }^{2}$ Histopathology Department, Cancer Research UK, Lincolns Inn Fields, London, UK; ${ }^{3}$ Histopathology Department, University College Hospital, London, UK; ${ }^{4}$ Histopathology Department, Bart's and The London, London, UK

Introduction Pseudopolyps develop as a result of mucosal ulceration and epithelial regeneration. ${ }^{1}$ They appear as islands of relatively normal epithelium in otherwise denuded mucosa and are the likely source of epithelium from which the mucosa repairs. They can be associated with areas of dysplasia but are thought to be benign. We have previously shown that protumourigenic mutations can spread through the entire colon in patients with UC-associated cancer. ${ }^{2}$ We hypothesise that pseudopolyps are clonal expansions of crypts that have acquired a protumourigenic survival advantage over surrounding normal epithelium that frequently perishes in the inflammatory milieu.

Methods To determine the genetic status of pseudopolyps and frequency of mutated pseudopolyps. DNA extracted from macrodissected UC-associated pseudopolyp tissue sections underwent nested PCR sequencing of common tumour suppressor and oncogenes known to be mutated in colitis associated cancers, using well established published protocols.

Results Of 30 pseudopolyp samples analysed from 30 different patients, four patients had identifiable mutations; in CDKN2A (c.C387T p.129Y), tP53-exon7 (c.C735T p.245G), and K-RAS (c.G37A p.G13S, and c.G35C p.Gly12Ala).

Conclusion We have shown that pseudopolyps are a potential source of protumourigenic mutations in UC. Pseudopolyps may possibly be the site within the inflamed epithelium where mutations are harboured, and may be the source for restituted bowel. More numbers are needed to be analysed and this is planned for future work and comparison with normal matched tissue is required. These lesions have been traditionally thought to be benign, genetically inert, incidental findings, characteristic of chronic inflammation. Although this data are preliminary, these findings propose an exciting paradigm shift in the way we consider pseudopolyps and may alter endoscopic management of these lesions in the future.

Competing interests None declared.

\section{REFERENCES}

1. Jalan KN, Sircus W, Walker RJ, et al. Pseudopolyposis in ulcerative colitis. Lancet 1969;2:255

2. Leedham SJ, Graham TA, Oukrif D, et al. Clonality, founder mutations, and field cancerization in human ulcerative colitis-associated neoplasia. Gastroenterology 2009; 136:542-50.

\section{PTU-125 POSITIVE CALPROTECTIN BUT NEGATIVE INVESTIGATIONS-WHAT NEXT?}

doi:10.1136/gutjnl-2012-302514c.125

${ }^{1} \mathrm{~N}$ Mohammed, * ${ }^{2} \mathrm{~S}$ Smale. ${ }^{1}$ Gastroenterology, Leeds Teaching Hospitals NHS Trust and Leeds Institute of Molecular Medicine, St James University Hospital, Leeds, UK ${ }^{2}$ Gastroenterology, York teaching Hospital NHS Foundation Trust, York, UK

Introduction Faecal markers are an increasingly established markers of gastrointestinal inflammation. Faecal calprotectin has an important role in differentiating functional from organic disease. ${ }^{1}$ However a small proportion of patients have an initial abnormal calprotectin and go on to complete normal series of gastrointestinal investigations. We submit this project where in we studied the outcome of those patients who had abnormal faecal calprotectin followed by normal endoscopic/radiological investigations for gastrointestinal diseases, over a period of 3 years.

Methods We identified all 600 patients in our unit who had faecal calprotectins performed between January and June 2007. We then selected all those with abnormal calprotectins $(>50 \mu \mathrm{g} / \mathrm{g})$ whose initial investigations were normal $(n=67)$ and assessed the long term follow-up of these patients.

Results All patients whose initial calprotectin was $<225 \mu \mathrm{g} / \mathrm{g}$ had not been found to have any inflammatory or neoplastic gastro-intestinal disease in the following 3 years follow-up. In those whose calprotectin was initially $>225 \mu \mathrm{g} / \mathrm{g}(\mathrm{n}=25)$ nine were found to have inflammatory bowel disease, 5 were found to have other organic pathology (Clostridium defficile associated Diarrhoea, Coeliac disease, Diverticular disease, Ischaemic colitis) over the subsequent 3 years. In those who had organic disease repeat calprotectin was elevated $(3 / 14)$. All other patients with an initial calprotectin of $>225 \mu \mathrm{g} / \mathrm{g}$ were concluded to have functional disease of whom $8 / 11$ had subsequent faecal calprotectins all of which were normal. Summary: 1. At a calprotectin of $<225 \mu \mathrm{g} / \mathrm{g}$ all patients were subsequently concluded to have functional disease. 2. Among those in whom initial calprotectin was $>225 \mu \mathrm{g} / \mathrm{g}$ with normal investigation only those with sequentially abnormal calprotectins (mean interval to second calprotectin 6 months, range 60-550 days) had organic disease on follow-up. Conclusion Negative faecal calprotectin can be a very useful tool to exclude organic pathology. Borderline positive results can be misleading. Serial Calprotectin may hold promise for defining those with post-inflammatory/infective IBS or organic disease. It also reflect response to treatment and aid in disease monitoring, but further longer term study is required.

Competing interests None declared.

\section{REFERENCES}

1. Tibble, et al. Gut 2000;47:506-13.

2. Limburg, et al. Am J Gastroenterol 2000;95:2831-7. 